Helgoländer wiss. Meeresunters. 30, 485-494 (1977)

\title{
Stabilizing properties of a high-biomass benthic community in a fluctuating ecosystem
}

\author{
J. OTT \& K. FEDRA \\ I. Zoologisches Institut der Universität Wien, \\ Lebrkanzel für Meeresbiologie und Abteilung für Ultrastrukturforscbung; \\ Vienna, Austria
}

\begin{abstract}
The shallow Northern Adriatic Sea is subject to strong seasonal and short-time fluctuations in climatic parameters and production. A high-biomass benthic epifauna community on sublittoral soft bottoms with biomass values of $370 \pm 73 \mathrm{~g}$ wet weight $\mathrm{m}^{-2}$, which consists of almost $90 \%$ filter feeders provides a storage compartment. This storage compartment exerts a regulatory effect on the total system metabolism through controlling watercolumn biomass and converting it to macrofauna biomass with a lower respiration: biomass ratio. Special adaptations of the brittle star Opbiotbrix quinquemaculata, the dominant species, to strong and rapid changes in temperature and oxygen saturation are discussed.
\end{abstract}

\section{INTRODUCTION}

Communities under a fluctuating physical regime can adopt two strategies: One is to conform with the external fluctuations acting as forcing functions in the system and to respond with corresponding variations in species composition, density and/or metabolism. An alternative is to develop mechanisms dampening the oscillations of the forcing functions. The change from the former to the latter strategy is believed to be a general trend in the evolution of ecosystems; the degree to which it is realized is regarded as a measure of the maturity of the system.

Many of these varying forcing functions directly or indirectly affect productivity, e.g. light and temperature in higher latitudes or seasonal precipitation and nutrient input through fluctuating river discharge. In these cases, storages may be developed in some part of the system (Odum, 1971). Generally, the storage is in form of organic compounds, either dead as in peat, litter and detritus in aquatic systems or in form of living biomass. For energetical reasons this is limited to primary producers or the first consumer level.

In order to be effective, the storage compartment has to contain a sizable part of the systems energy content and nutrients. Storage in form of large individuals results in lower maintenance cost (respiration : biomass ratio), although total energy flow may be high. This strategy is, therefore, most effective in systems with fluctuating but on the average high productivity. 
On the other hand, the component species have to have adequate physiological mechanisms to make them metabolically more or less independent from the fluctuating external conditions and to protect the quantity stored in them in extreme situations, since failure of a singly large storage compartment would lead to dangerous short circuiting of the potential energy it contains.

We want to examine a high biomass epifaunal community in the Northern Adriatic Sea (Fedra et al., 1976) and to investigate whether it shows the above characteristics and thus may serve as a stabilizing compartment in this shallow sea.

\section{HYDROGRAPHIC PROPERTIES OF THE NORTHERN ADRIATIC SEA}

Due to its position in a fairly high latitude (roughly between $44^{\circ}$ and $46^{\circ} \mathrm{N}$ ) the Northern Adriatic Sea is subject to considerable seasonal fluctuations in air temperature and radiation. The seasonally varying river discharge and its shallowness (less than $40 \mathrm{~m}$ for the greatest part) furthermore add to its instability and render it among those parts of the Mediterranean Sea with the highest amplitudes of climatic factors during the year. The most recent surveys of its hydrology and productivity were done in 1965 by Stirn (1969) and Franco (1970, 1972a, b), and on a more regional basis for the area of our investigations by Tušnik (1976) for the years 1972-1975. A further characteristic is a high level of inorganic nutrients and consequently pelagic production, which ranks it among the most fertile parts of the Mediterranean Sea.

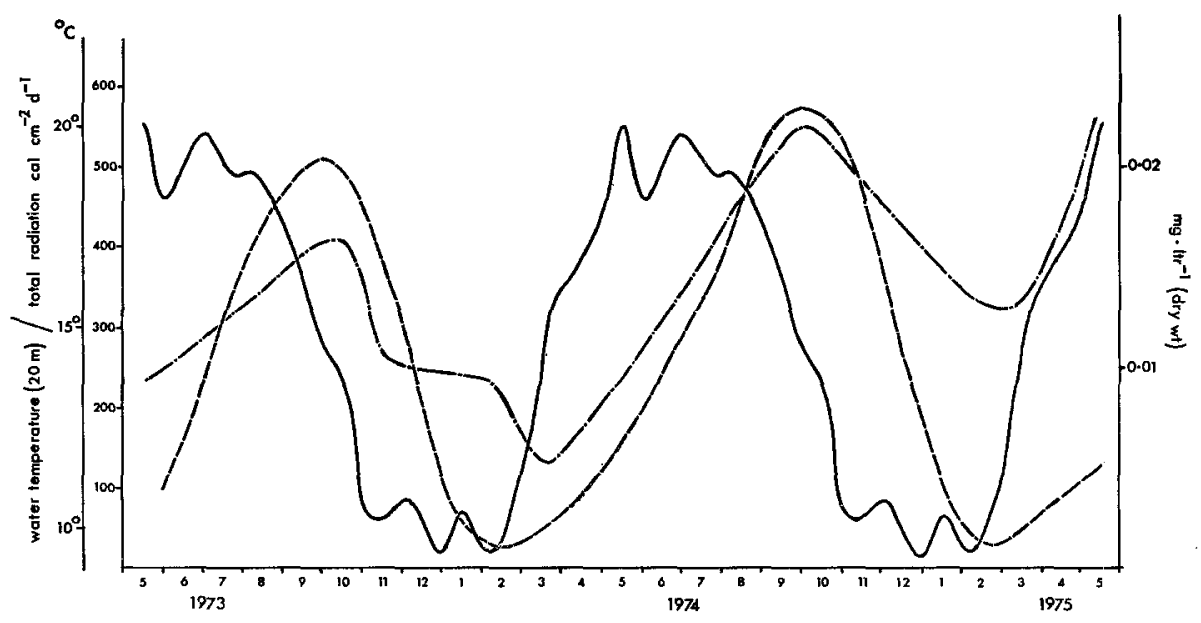

Fig. 1: Seasonal fluctuations in total radiation, temperature (20m depth), and zooplankton in the Northern Adriatic Sea. Radiation curve for 1965 (from Franco, 1972), temperature and zooplankton for years indicated (J. Stirn, personal communication)

Figure 1 is compiled from the above sources, including total radiation, temperature, and zooplankton, showing the typical seasonal fluctuations for a shallow temperate sea. Besides these seasonal patterns of fluctuations, which are characteristic 
for the larger part of the water column, the benthos has to cope with additional irregular short-term fluctuations in temperature and $\mathrm{pO}_{2}$. Evidence for these dramatic fluctuations has been gathered during investigations of oxygen uptake of the sea bottom in $23 \mathrm{~m}$ depth near Piran, Yugoslavia (Ott \& Machan, in preparation) in August and September 1974. During calm weather conditions a strong thermic stratification persists. Below the thermocline, an oxygen deficit develops which may be further aggravated by the appearance of a cold $\left(17^{\circ} \mathrm{C}\right)$ water body, which forms a layer of about $2 \mathrm{~m}$ thickness above the bottom, having especially low $\mathrm{O}_{g}$ concentration. This water mass may be an extension of the eastern core of cold water penetrating from the Middle Adriatic Sea presumably along the Istrian coast (Franco, 1970; p. 7). The layering may be destroyed within a few hours in the case of a strong wind like the frequent "Bora", after which the water column is isothermal and saturated throughout.

\section{BENTHIC FAUNA}

Rich epifaunal communities are known from several locations in the Northern Adriatic Sea, especially along the coast of the Istrian Peninsula (Czihak, 1959; Riedl, 1961), and the Gulf of Triest (Orel \& Mennea, 1969). Fedra et al. (1976) made a detailed study of an area of more than $200 \mathrm{~km}^{2}$ along the coast of SR Slovenia using a ship towed TV sled (Machan \& Fedra, 1975) and diver taken samples.

It should be noted in this context, that with the exception of Orel \& Mennea who used 121 grab samples - all investigations in which high epifauna biomass was reported employed visual means such as TV or bottom cameras, whereas older surveys based on few grab samples, as Vatova $(1943,1949)$ failed to detect anything but scarce endofauna.

Further cruises in the Italian part of the Gulf of Triest brought new evidence about the wide distribution of rich epifaunal communities (Fedra \& Stefanon, in prep.). These epifauna assemblages vary in species composition, most data however, come from a relatively homogeneous association, which covers the greatest area and has been named the Ophiothrix-Reniera-Microcosmus-community by Fedra et al. (1976). Below the 20 isobath the sediment, which is muddy to sandy, is covered with clumps of sedentary animals, mainly sponges and ascidians. The most abundant vagile animal species is the brittle star Ophiothrix quinquemaculata, which reaches numbers up to 500 individuals $\mathrm{m}^{-2}$. Total epifauna biomass in the central part was $370( \pm 73) \mathrm{gm}^{-2}$. $87.5 \%$ of this biomass is composed of suspension feeders. In this way the benthos is in its greatest part directly linked with the pelagic system, only $5 \%$ are deposit feeders. $28 \%$ of the community's biomass is represented by $O$. quinquemaculata, a passive filter feeder, $20 \%$ by sponges of the genus Reniera and $16 \%$ by the ascidian genus Microcosmus, both active filter feeders.

\section{STABILITY OF THE BENTHOS}

The central area of this community has been visited regularly during 4 years. The general impression was of an absence of seasonal changes in biomass and species 
composition. All the quantitatively important species are perennial, reproduction and settlement of young (data from Ophiotbrix and the sea cucumber Cucumaria planci) occur throughout the year, however with a peak in gonad weight in late spring and the most settlement in late summer. Artificial substrates are immediately colonized and undergo rapid successions, however, none of the stages observed ressemble the multi-species aggregations that are typical for the community. Recruitment of these aggregates is obviously linked to a complicated interspecific regulatory mechanism (Stachowitsch, in press).

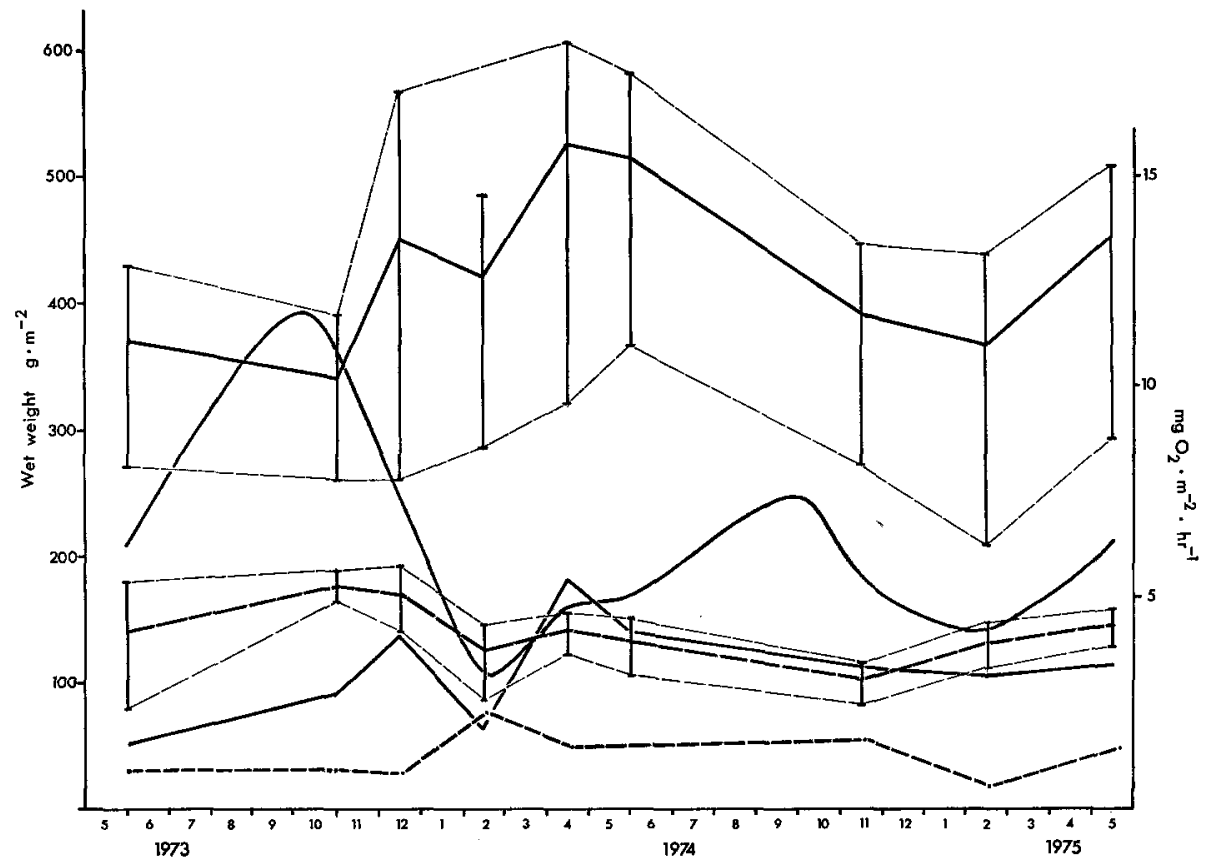

Fig. 2: Fluctuations in total community biomass (upper solid line), biomass of Ophiotbrix quinquemaculata (upper broken line), Reniera ssp. (lower solid line), Microcosmus ssp. (lower broken line) and oxygen uptake by the Opbiotbrix population (curve). The $95 \%$ confidence limits are drawn for total community biomass and Opbiotbrix biomass. (Data from Fedra, in preparation)

During two years (from May 1973 to May 1975) quantitative samples were taken in nine series on three positions within the community. A total of $147 \mathrm{~m}^{2}$ were sampled by SCUBA divers (for treatment of the samples see Fedra, in press). Mean total community biomass for the 9 series together with the $95 \%$ confidence limits is plotted in Figure 2. Although there is a trend towards higher biomass values in spring, the difference between the mean of the maximum and the minimum was not significant at the 0.05 level. Together with the total biomass data, the values for the three genera, which constitute together on the average $64 \%$ of the community's biomass, are given. The large, slow growing sponges of the genus Reniera show no significant change in 
biomass over the investigation periods, although the difference in mean appears greatest. This is due to the great sampling error in this highly aggregated species. Biomass variations in Microcosmus ssp. and Ophiotbrix quinquemaculata, the smallest of the main species, are significant, although very small. As an estimate for total community metabolism the $\mathrm{O}_{2}$ consumption rate for a square meter of the Ophiothrix population - which accounts for approximately $60 \%$ of the oxygen uptake of the macroepifauna - is also shown.

\section{RELATIVE IMPORTANCE OF THE BENTHOS}

The first question that arises is, whether the benthos may be considered as an important storage compartment in the system. For a comparison of biomass and metabolism between benthos and the water column, unpublished data for the latter have been kindly supplied by the Marine Biological Station, Portoroz. Oxygen-uptake values for the sediment and the water column are from Ott \& Machan (in prep.). Values for the macrofauna are taken from Fedra (in press) and Fedra et al. (in prep.). Values and relationships are given for November 1974.

The average standing crop of the macro-epibenthos was $98500 \mathrm{cal} \mathrm{m}^{-2}$. The water column above such a square meter contained estimated $63000 \mathrm{cal}$ of seston (particulate organic matter retained by a $0.47 \mu \mathrm{m}$ filter). Zooplankton biomass was about 1100 cal. Unfortunately we have no data about dissolved organic matter.

Benthic macro-epifauna respiration amounted to $920 \mathrm{cal} \mathrm{m}^{-2} \mathrm{day}^{-1}$. If we assume an assimilation efficiency of $30 \%$ and steady-state conditions for the total macro-epibenthos (so that respiratory demand equals the energy assimilated), approximately $3000 \mathrm{cal}$ will be ingested daily by the epifauna. This compares well with the values derived from filtration rates by Olscher $\&$ Fedra (in press), who give a range of $2250-4500 \mathrm{cal}$. This means that the macro-epibenthos would need about three times the quantity of zooplankton present in the water column or $5 \%$ of the total seston to cover its maintenance needs. The egested fraction is in its greatest part used up by the sediment, which consumes 1100 to $1600 \mathrm{cal} \mathrm{m}^{-2}$ day $^{-1}$.

Respiration in the heterotroph part of the water column (below $5 \mathrm{~m}$ at this time) utilizes estimated $25000 \mathrm{cal} \mathrm{m}^{-2}$. The organic matter in the water column contributes, therefore, the major part of the system's respiration. If the benthos could control the quantity of suspended organic matter - and we have to remember in this context that $87.5 \%$ of the macro-epibenthos consists of suspension feeders - it could control the system's oxygen uptake. If we assume that oxygen uptake is proportional to the amount of organic matter in the respective compartment (this will certainly hold true for the plankton and seston, where the size of organisms and particles will be constant and the increase will be in numbers, but will be less in the benthos, where at least part of a biomass increase will be in the form of increasing organism size), a simple calculation shows that an increase in seston of $100 \%$, in the case that it is not taken up by the benthos, will increase the oxygen uptake of the total system by more than $90 \%$. However, if this excess is cropped by the benthos and converted to its biomass, the total respiratory demand of the system will increase by only $2 \%$. 
Figure 3 shows the relative change in total system respiration when the total organic matter in the water column is increased by a factor of $k$ for various proportions of benthic to water column biomass. The storage capacity of the benthos has been limited to a certain fraction of its own biomass. It is evident, that there is an optimum biomass relationship between the two compartments, in which the regulation is most effective, bordered towards the right, where the storage capacity of the benthos becomes insignificant and towards the left, where the change in water column biomass becomes insignificant. For a storage capacity of $50 \%$ of its own biomass - which seems reasonable for the variations observed in our community - optimum regulation would be at a ratio of water column biomass to benthic biomass of $1: 2$. The actual values as given above, are about $1: 1.5$ in our system.

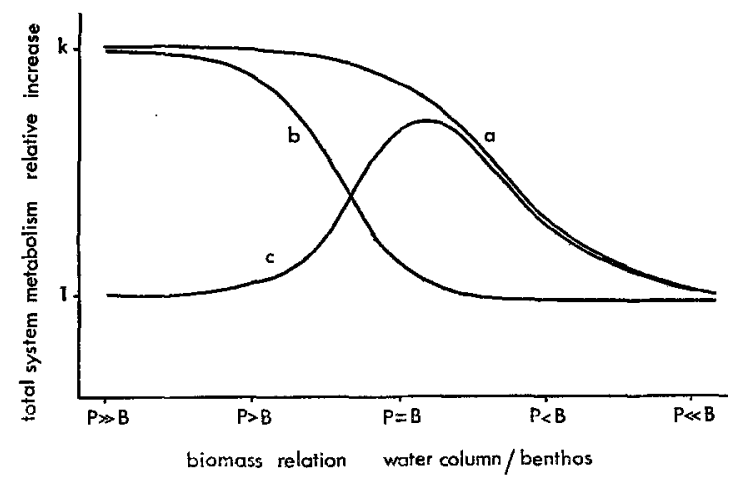

Fig. 3: Change in total metabolism of a water-column benthos system after water-column biomass increased by factor $k$ for various relative proportions of water column $(P)$ to benthic biomass (B). $a$ excess water column biomass not cropped by benthos; $b$ excess biomass cropped by benthos to a new equilibrium state; $c$ regulatory capacity $(a: b)$. The position of the maximum depends on the maximum possible biomass increase in the benthos and its removal efficiency

Evidence that the benthos controls the amount of suspended organic matter is obtained from the range of variation of phytoplankton and seston between surface and bottom layers. Phytoplankton (measured as sum of chlorophyll $a+b+c$ ) varied by a factor of 9.4 in the surface, 3.9 in the bottom water, organic matter in the seston by a factor of 3 in the surface, and of 2 in the bottom layer between July, 1974 and May, 1975.

A necessary prerequisite for an effective regulation of total systems metabolism is the availability of the organic matter in the whole water column to the benthos. This requires a high degree of mixing. In late summer, however, the very stable thermal layering mentioned above may persist for prolonged periods, disrupting the regulatory process. In August, 1974 we observed two distinct thermoclines on our permanent station off Piran. One, between 5 and $10 \mathrm{~m}$ and one, between 2 and $5 \mathrm{~m}$ above the bottom. Between the thermoclines, density of particulate organic matter increased strongly and oxygen saturation dropped below $80 \%$. Below the second thermocline, the water was only $25 \%$ saturated for several days. The combination of physiological stress and the changed biomass ratio between water column and 
benthos - which would mean that the system would operate outside its optimum regulatory range - may, even after mixing, lead to a persistence of an oxygen deficit and result in mass mortality of the benthic fauna.

Evidence that such a breakdown of the system may occur regionally is shown in the large areas (several $\mathrm{km}^{2}$ ) where all the macrobenthos was found dead during TV transects (Fedra et al., 1976). Whether this breakdown is mediated by man-made pollution adding to the organic load of the system or a natural phenomenon limiting the distribution of the high biomass communities described is open to debate. However, the frequency of these regional catastrophes has to be low in order to allow the system to function effectively. Therefore, we have to expect physiological mechanisms in the component species to survive stress conditions for their average duration and to regulate their metabolism within wide limits.

\section{SPECIAL ADAPTATIONS IN OPHIOTHRIX QUINQUEMACULATA}

Thus far, we have only investigated the dominant species, Ophiotbrix quinquemaculata thoroughly. Parameters of interest were mainly temperature and oxygen

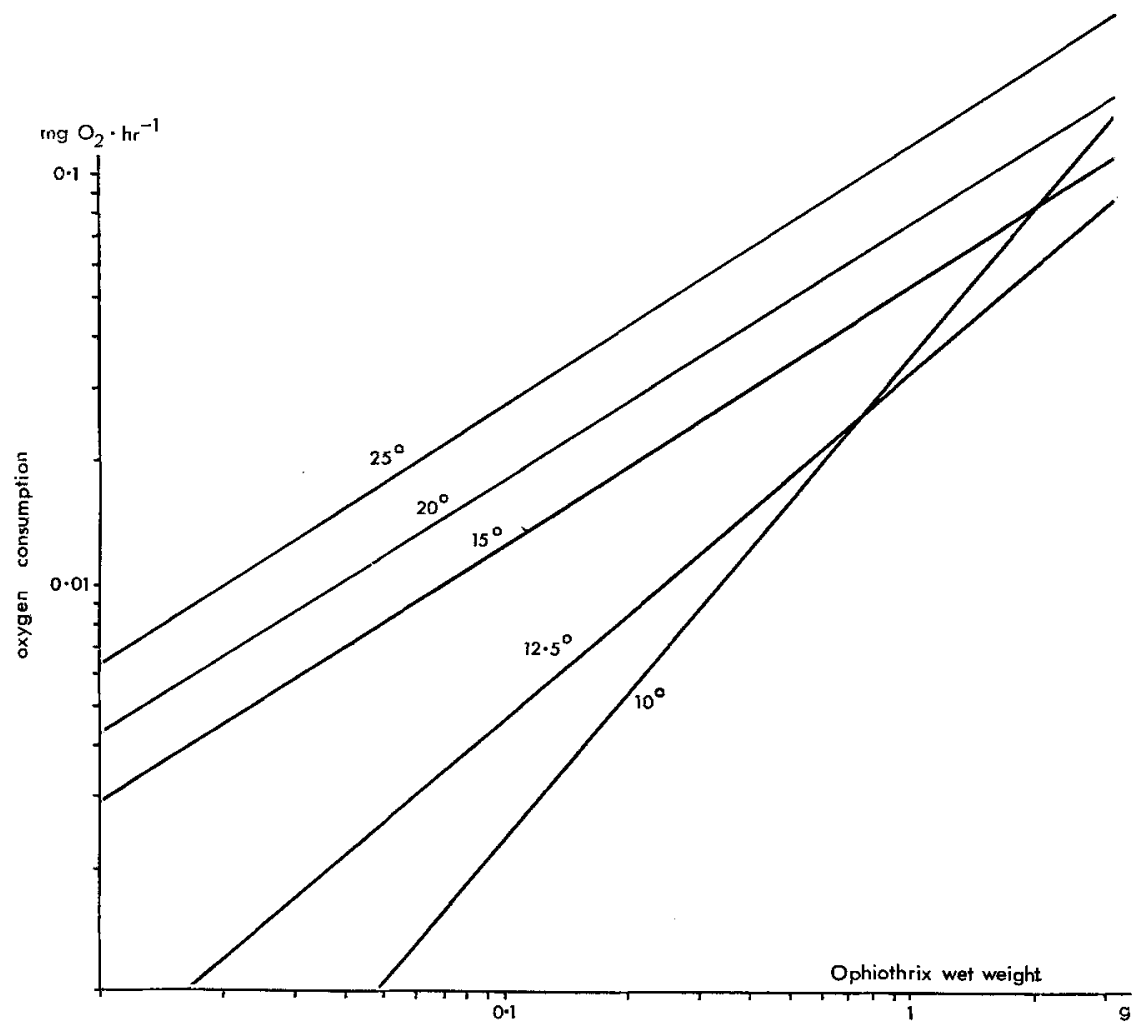

Fig. 4: Opbiothrix quinquemaculata. Oxygen consumption at different temperatures 
saturation; both may change dramatically within a short period of time. Ott $\&$ Machan (in prep.) observed temperature changes of $3^{\circ} \mathrm{C}$ within $6 \mathrm{~h}$ and from slightly supersaturated conditions $(108 \%)$ to $26 \%$ within less than $24 \mathrm{~h}$.

Figure 4 shows the regressions of $\mathrm{O}_{2}$ uptake of Ophiotbrix quinquemaculata against wet weight for various temperatures within the ecological range of the species (Fedra et al., in prep.). A three-variable regression of $\mathrm{O}_{2}$ uptake against weight and temperature showed a linear relationship with the latter, indicating a regulatory plateau. Ophiotbrix quinquemaculata regulates its respiration most effectively in the upper limit of its ecological range (between $15^{\circ}$ and $20^{\circ} \mathrm{C}$ ). At these temperatures the lowest oxygen saturation values occur. Towards the lower limit of its temperature range the brittle star begins to conform.

The relationship of oxygen uptake and $\mathrm{O}_{2}$ saturation is shown in Figure 5. Again it is apparent that Opbiotbrix quinquemaculata can regulate its own oxygen uptake at temperatures of $15^{\circ}$ and $20^{\circ} \mathrm{C}$ effectively down to about $20 \%$ saturation, which is the lower limit of natural oxygen concentrations observed to have been endured for some days. At these concentrations in nature they do not assume the filtering posture any more. At $25^{\circ} \mathrm{C}$, a temperature they may not experience in nature, they are conformers. These data have been derived from prolonged runs in respiration chambers, where the brittle stars themselves reduced the oxygen concentration in the system. The conspicous increase at slightly lowered saturation values may be a result of increased activity, either after getting accustomed to the chamber, or as a result of a direct stimulus of decreasing oxygen concentration. This behaviour in nature may serve to find elevated places away from the boundary layer.

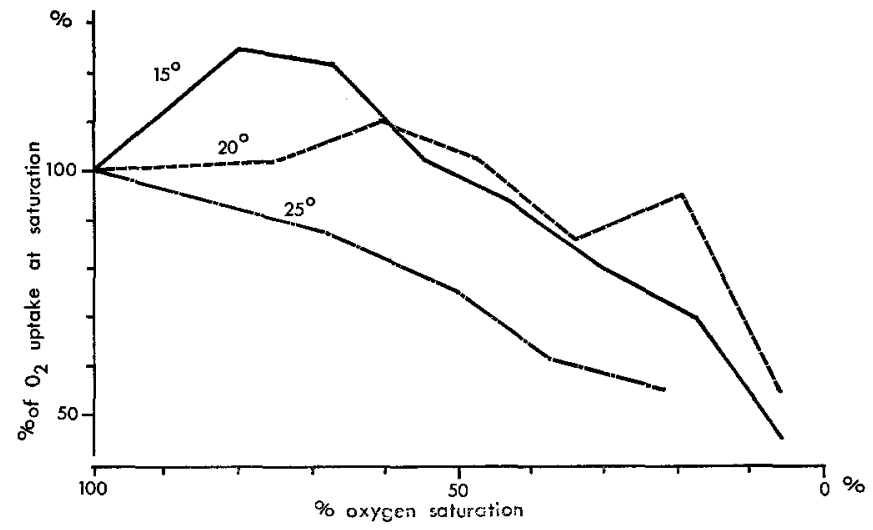

Fig. 5: Ophiothrix quinquemaculata. Oxygen consumption in water of different oxygen saturation in relationship to the consumption of the same individuals at $100 \%$ saturation. Data

for each temperature derived from several $(n=7-12)$ specimens of different size classes

\section{DISCUSSION}

Frank (1965) comments on the similarity of benthic animal communities of high biomass to the biomass of terrestrical primary producers, which also has a stabilizing 
function. The most striking difference between the terrestrical and the marine situation is, that the best example for large storage in the primary-producer level is the tropical rain forest which developed in an already physically stable environment, whereas in the sea high-biomass communities are known from fluctuating environments like estuaries and temperate shallow waters. We have to go back to our statement presented in the introduction: one feature of a storage compartment is that, although maintenance cost per unit biomass is low, total energy flow is rather high. In the terrestrical situation, the areas of highest productivity are the moist tropical regions. Here, the development of stabilizing storages can be afforded although they appear almost as a "luxury" which, together with the already low variability of the environment, create a "superstability".

Tropical marine waters exhibit comparatively low productivities and may not be able to "afford the luxury" of additional stabilizing storages. However, in the productive estuaries and shallow temperate seas, total energy flow is sufficiently high; at the same time, the selective value of the biological stabilizing mechanism within the system appears to be greater. In these cases, stabilizing mechanisms are no "luxury" but a "necessity". Towards the poles low productivity again limits the development of costly storage compartments in both marine and terrestrical environments.

Acknowledgements. This study was supported by projects No. 1940 and 2758 of the "Fonds zur Förderung der wissenschaftlichen Forschung, Austria". The authors' thanks are due to Yugoslavian authorities for research permits and their hospitality, and to director and staff of the Marine Biological Station, Portoroz.

\section{LITERATURE CITED}

Czihak, G., 1959. Vorkommen und Lebensweise der Opbiotbrix quinquemaculata in der nördlichen Adria bei Rovinj. Thalassia jugosl. 1, 19-27.

Fedra, K. Structural features of a North Adriatic benthic community. In: European marine biological symposium 11 (in press).

- Olscher, E., Scherübel, C., Stachowitsch, M. \& Wurzian, R., 1976. On the ecology of a North Adriatic benthic community: distribution, standing crop and composition of the macrobenthos. Mar. Biol. 38, 129-145.

Franco, P., 1970. Oceanography of the Northern Adriatic Sea. I. Hydrological features: Cruises July-August and October-November 1965. Archo. Oceanogr. Limnol. 16 (Suppl.), $1-93$.

- 1972a. Oceanography of the Northern Adriatic Sea. II. Hydrological features: Cruises January-February and April-May 1966. Archo. Oceanogr. Limnol. 17 (Suppl.), 1-97.

- 1972b. Oceanography of the Northern Adriatic Sea. III. Distribution of the water transparency: Cruises July-August and October-November 1965, January-February and AprilMay 1966. Archo. Oceanogr. Limnol. 17 (Suppl.), 99-113.

Frank, P., 1968. Life histories and community stability. Ecology 49, 355-357.

Odum, E. P., 1971. Fundamentals of ecology. Saunders, Philadelphia, 574 pp.

Olscher, E. \& Fedra, K. On the ecology of a suspension feeding benthic community: filter efficiency and behaviour. In: European marine biological symposium. 11, (in press).

Orel, G. \& Mennea, B., 1969. I populamenti bentonici di alcuni tipi di fondo mobile del Golfo di Trieste. Pubbl. Staz. zool. Napoli 37, 261-276.

Riedl, R., 1961. Etudes des fonds vaseux de l'Adriatique. Méthodes et résultats. Recl Trav. Stn mar. Endoume 23, 161-169. 
Stachowitsch, M. The hermit crab microbiocenosis - the role of mobile secondary hard bottom elements in a North Adriatic benthic community. In: European marine biological symposium. 11, (in press).

Stirn, J., 1969. Pelagical Severnega Jadrana. Razpr. slov. Akad. Znan. Umet. 12, 1-92.

Tusnik, P., 1976. Osnovne znacilnosti fizicnega okolja v obalnem morju slovenskega primorja. Magistrsko delo, Univ. Ljubljana, 64 pp.

Vatova, A., 1943. Le zoocenosi dell'Alto Adriatico presso Rovigno e le loro variazioni nello spazio e nel tempo. Thalassia 5 (6), 1-61.

- 1949. La fauna bentonica dell'Alto e Medio Adriatico. Nova Thalassia 1 (3), 1-110.

First author's address: Dr. J. Ott

Zoologisches Institut

Universität Wien

Währingerstr. 17

A-1090 Vienna

Austria 